Supplement of Atmos. Chem. Phys., 14, 7045-7057, 2014

http://www.atmos-chem-phys.net/14/7045/2014/

doi:10.5194/acp-14-7045-2014-supplement

(C) Author(s) 2014. CC Attribution 3.0 License.

(c) (1)

Supplement of

\title{
Dispersion of the Nabro volcanic plume and its relation to the Asian summer monsoon
}

\section{T. D. Fairlie et al.}

Correspondence to: T. D. Fairlie (t.d.fairlie@ nasa.gov) 


\section{Supplemental Material}

\section{A. Ash as a minor component of the Nabro plume}

Figure $\mathrm{S} 1$ shows a scatter plot of volume depolarization ratio, $\delta$, vs. scattering ratio (SR) at $532 \mathrm{~nm}$ from CALIPSO observations made between 14 and $20 \mathrm{~km}$ altitude in the domain $0-60^{\circ} \mathrm{N}, 0-150^{\circ} \mathrm{E}$ for the first 20 days following the Nabro eruption. The data are colored by 1064/532 nm color ratio (CR). Two main clusters are evident in Fig. S2: (i) low $\delta(<\sim 5 \%)$ with CR values of $\sim 0.2-0.3$, characteristic of sulfate aerosol, and (ii) relatively high $\delta$ increasing with SR, characteristic of ice clouds. In the first few days after the eruption, the plume occasionally shows depolarization values greater than $5 \%$, likely due to the presence of ash particles (points with $\delta>5 \%$ but below the black line in Fig. S2). Thus, the CALIPSO data indicates ash as a minor component of the Nabro volcanic plume; hence we use the more restrictive constant threshold of $\delta=$ $5 \%$ to isolate the volcanic plume (mainly sulfate) from the ice clouds.

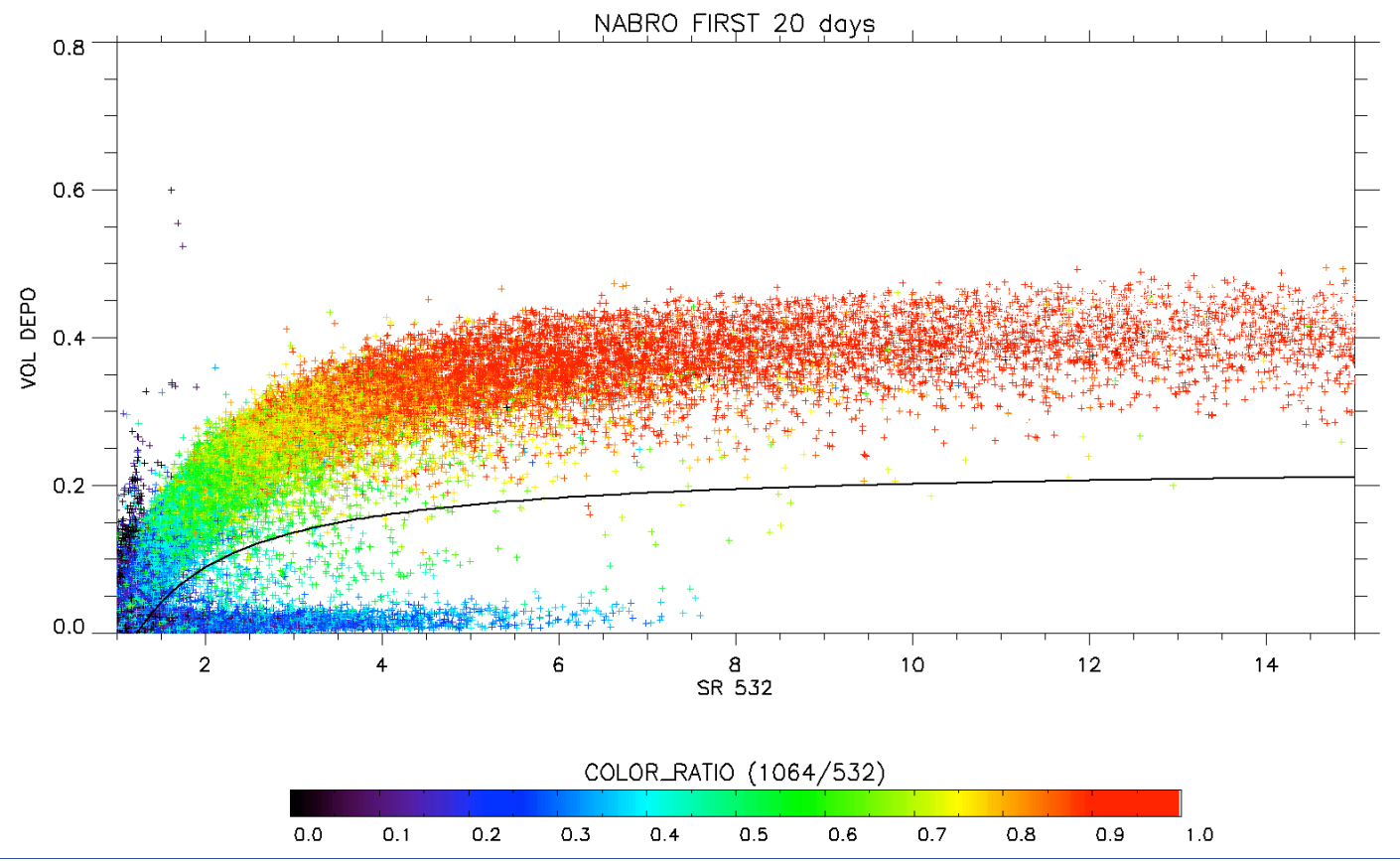

Figure S1: Scatter plot of CALIPSO 532nm volume depolarization ratio vs. scattering ratio for 15 June - 5 July, 2011 for $14-20 \mathrm{~km}$ altitude in the domain $0-60^{\circ} \mathrm{N}, 0-150^{\circ} \mathrm{E}$. The data are averaged in $1 \mathrm{deg}$. latitude and $200 \mathrm{~m}$ altitude intervals on orbital tracks, and are colored by 1064/532 color ratio. The black line represents an empirical separation between the volcanic plume and ice clouds. Points associated with very low depolarization $(<5 \%)$ have the optical characteristics of sulfate 
B) Magnitude of radiative forcing

Figure S2 shows a time series of monthly-mean CERES TOA outgoing SW radiative flux anomalies, between $50^{\circ} \mathrm{S}$ and $50^{\circ} \mathrm{N}$. The standard deviation (s.d.) of the monthly values is $\sim 0.2 \mathrm{Wm}^{-2}$, of similar magnitude to the our estimates of total clear sky TOA RF for the months following the Nabro eruption, based on CALIPSO observations. The figure shows generally positive anomalies (enhanced outgoing SW) from mid 2010 - mid 2012, but the increase precedes rather than coincides with the Nabro eruption.

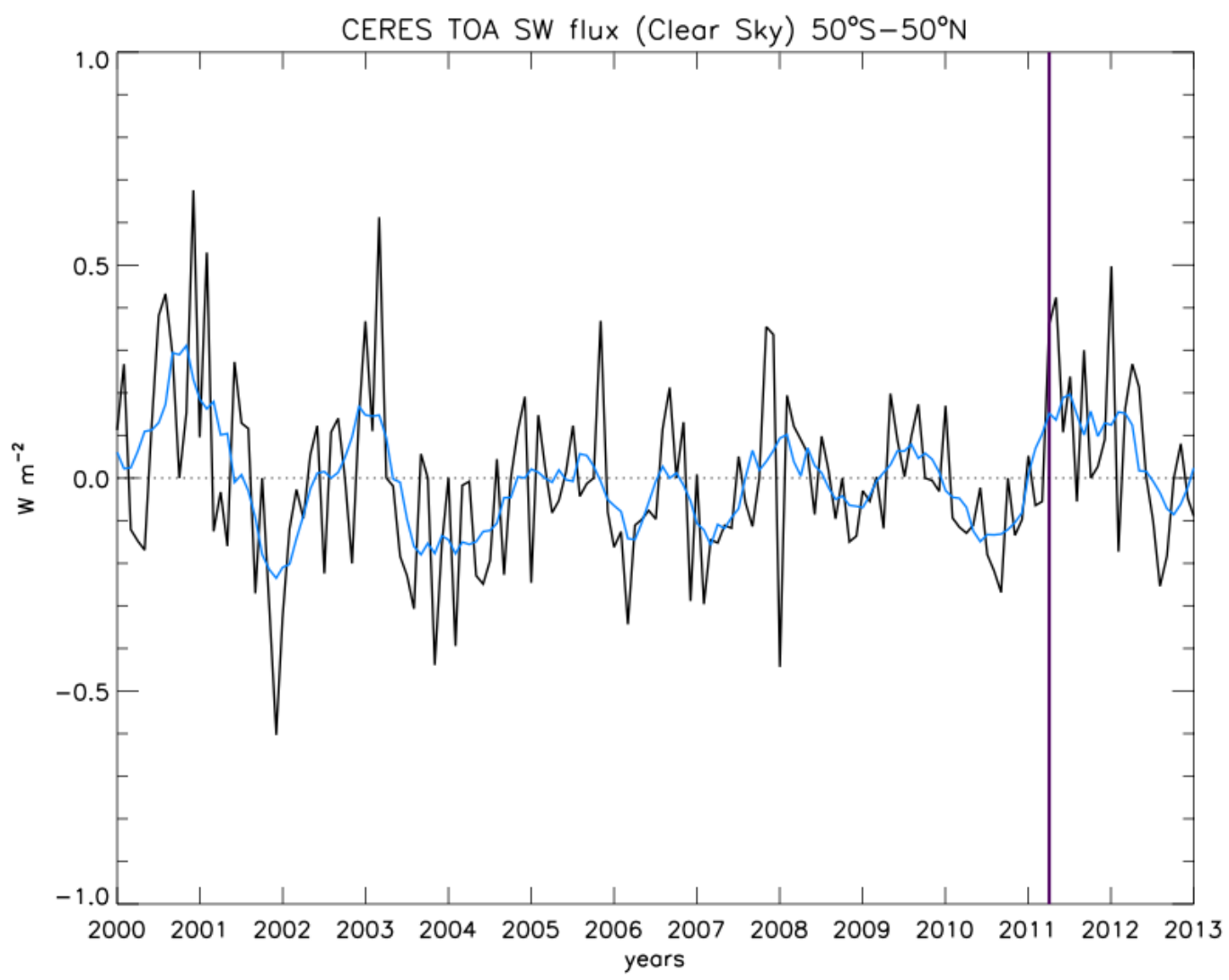

Figure S2: Time series of zonal-mean, monthly-mean TOA outgoing SW radiative flux anomalies from CERES observations, averaged between $50^{\circ} \mathrm{S}$ and $50^{\circ} \mathrm{N}$ from March, 2000 - June, 2013. Anomalies are obtained by removing the 13-year monthly mean from each month's data, which de-seasonalizes the data. Monthly means are shown in black; six-month box-car averages are shown by blue curve; time of Nabro eruption is shown by vertical purple line; ticks on the abscissa mark March means for each year. 